\title{
Teoria em ato: o que pode e o que aprende um corpo?
}

Cristian Poletti Mossi'

\section{Resumo}

No intuito de retomar a célebre pergunta feita por Spinoza "0 que pode um corpo?" -, o artigo sustenta sua problemática em torno da questão "O que pode e o que aprende um corpo?" Nesse sentido, procura-se percorrer algo que no texto é designado como uma teoria em ato. Para tanto, num primeiro momento, busca-se elucidar as possibilidades teóricas e os locais de fala utilizados operacionalmente para produzir tal construção. Apoiase a noção de um corpo fendido, ou seja, um corpo que se abre para outras possibilidades de ser corpo, distantes das comumente instituídas (corpo autônomo, consciente, racional) e, desse modo, produz uma teoria em ato que não mais reconhece a clássica separação corpo versus mente (alma, pensamento). Em seguida, associa-se à referida questão-problema a prática do corpo-semórgãos, cunhada pelo dramaturgo francês Antoni Artaud em sua conferência radiofônica de 1947 (Pour en finir avec le jugement de dieu) e retomada por Deleuze e Guattari em sua ampla produção filosófica com o intuito de, desse modo, propor a ação de pensar como fluxo que atravessa os atos de ler e escrever em meio à vida enquanto esteiras de criação e invenção, ao passo que não somente representam, mas produzem realidades.

\section{Palavras-chave}

Corpo - Corpo-sem-órgãos - Teoria em ato - Educação Escrita - Leitura. 


\title{
Theory in act: what can a body do and what does it learn?
}

Cristian Poletti Mossi'

\begin{abstract}
With the purpose of resuming the notorious question asked by Spinoza - What can a body do? -, this paper supports the assertion of What can a body do and what does it learn? Thus, I attempt to cover what in the text is designated as a theory in act. For such, at a first stage, I try to elucidate the theoretical possibilities and the places of speech operationally utilized to produce such construction. I support the notion of a cracked body, that is, a body that opens itself to other possibilities of being a body, away from the commonly instituted manners (autonomous, conscious, rational body) and, as a result, a theory in act is produced which no longer acknowledges the classical separation of body against mind (soul, thinking). Next, the issue-problem is referred to the practice of the organ-less-body, minted by French playwright Antoni Artaud in radio broadcast conference in 1947 (Pour en finir avec le jugement de dieu) and resumed by Deleuze and Guattari in their wide philosophical production with the purpose of, consequently, propose the action of thinking as a flow that goes through the acts of reading and writing amidst life taken as tracks of creation and invention, while they not only represent but also produce realities.
\end{abstract}

\section{Keywords}

Body - Organ-less-body - Theory in act - Education - Writing - Reading.

I- Universidade Estadual do Rio Grande do 


\section{O que pode e o que aprende um corpo?}

Poderíamos iniciar este texto de inúmeras formas; contudo, optamos - correndo o risco de cairmos nas diversas armadilhas palavroides que a língua pode nos impor -, por começálo com uma afırmação: a educação, ou melhor, a Educação - escrita assim, em caixa alta -, a Grande Educação, Educação Maior, focada na aprendizagem de conteúdos fechados, e não ao sabor dos encontros que por ventura podem instigar o pensamento a pensar, como nos propõe Deleuze (2006), parece ter nos feito esquecer que temos corpo. Ou melhor, deunos momentos específicos e bem datados para lembrarmos que temos um. E nos fez pensar que temos um só.

Sem dúvida (e está aí uma das ciladas em que de início podemos cair lançando essa afırmativa), não podemos pensar que tal façanha seja atribuída somente aos estratos que conjuram a Educação, mas sim que também deve sê-lo aos mais variados estratos e substratos que atravessam aqueles, que contribuem para sua formação e calcificação, tais como toda sorte de correntes teóricas, filosóficas, midiáticas, pedagógicas, sociais, políticas, dentre outras. Ao situarmos a Educação como único e sagrado lugar para as aprendizagens, revogamos o corpo que transita por inúmeros outros trajetos e o situamos em um espaço-tempo onde se entrecruzam linhas e dispositivos muito específicos.

Quando deambulamos pela temática do corpo em educação, quando somos incitados a recordar que temos corpo, vez ou outra, é de um tipo muito específico de corpo que somos lembrados: um corpo que pode ser útil, o corpo disciplinado, o corpo dócil, letrado, capaz de seguir e repetir padrões pré-datados, pré-formulados. Ainda nesse preâmbulo, a tradicional questão lançada por Spinoza - "0 que pode um corpo?" -, parece ter se tornado esquecida, soterrada, encoberta por uma série de estratificações, as quais não só separam, ao modo cartesiano, o corpo da mente, como também dão um lugar de status a essa segunda instância - esse segundo modo, como nos diria o mesmo filósofo, preocupado com os afetos de que um corpo é capaz e com a mente (a alma, o pensamento) apenas como uma ideia do corpo.

A questão que parece se colocar como primordial é oriunda de o que pode uma mente, uma alma e um pensamento "bem formados", como se houvesse um tipo de possibilidade de contaminação no que envolve o corpo em carne e osso, capaz de turvar ou embaralhar uma verdade asséptica a ser buscada a todo o custo.

Tentando trabalhar em outra esteira e entendendo corpo/mente enquanto instâncias inseparáveis, podemos ainda nos perguntar "O que pode e o que aprende um corpo?" Ao lançarmos tais problemáticas, procuramos nos referendar não ao corpo consciente, unânime, bem ajustado, funcionando mecanicamente, organicamente, hierarquicamente (o corpo que parece ser útil à educação), mas sim a um corpo esquizoide, corpo do esquecimento, corpo maquínico, conectado a toda sorte de outros corpos, em que nenhum é o centro dos processos. Um corpo polifônico que se faz, refaz e perfaz na antropofagia de outros corpos, em meio às instâncias da escrita/ leitura - escrileitura -, "expressão mascarada da escrita-pela-leitura e da leitura-pela-escrita bravos combates das máquinas de guerra" (CORAZZA, 2008, p. 21) -, atravessado por imagens dotadas de vida que pulsa, que escapa, que impossibilita qualquer tipo de sobrecodificação burocrática, engessada.

Nesse sentido, se dizemos que a Educação (e, como já dito, conjuntamente outros estratos), essa das grandes pedagogias e metodologias, essa grande educação, nos fez esquecer que temos um corpo, é com esse segundo corpo, corpo-menor - esse corpo dotado de uma potência de singularidade - que aqui procuramos trabalhar.

Spinoza propõe aos filósofos um novo modelo: o corpo. Afirma que jamais saberemos do que um corpo é capaz. Essa declaração de 
ignorância parece ser uma provocação, na medida em que falamos da consciência e de seus decretos, da vontade e de seus efeitos, dos mil meios de mover o corpo, de dominar o corpo e as paixões; mas nós nem sequer sabemos quais as potências que guarda um corpo. Porque não o sabemos, tagarelamos, espantamo-nos diante da consciência e da ignorância. Tentamos transcender a carne. Contudo, o que continua a surpreender é ainda o corpo em si mesmo.

Assim, se procuramos replicar na diferença a pergunta de Spinoza anteriormente citada e trazê-la para o campo educativo na tentativa de pensá-la especificamente no que concerne às possibilidades e às aprendizagens de que um corpo é capaz, não é porque tal questão tenha uma resposta fixa que necessitaria ser buscada arduamente, uma resposta mais profunda que precisa ser trazida à luz. Justo pelo contrário, ela provoca em nossos terrenos, nos agenciamentos territoriais estratificados (DELEUZE; GUATTARI, 1995b) dos quais participamos e que há muito pouco nos pareciam perfeitamente estáveis, diversos abalos - como abalos sísmicos - que defloram nosso pensamento e o colocam a pensar na possibilidade de uma teoria em ato, uma teoria vascularizada que só se faz na ação, na incorporação.

Se o pensamento não é algo natural e que ocorre a todo o tempo, como tão bem nos lembra Deleuze (2003; 2006), é porque ele não é oriundo da mente como sua gênese, como centro de emanação de teorias, conceitos, ideias, princípios etc., mas, sim, oriundo do encontro com signos que nos afetam, que potencializam nosso corpo e mobilizam nosso pensamento a pensar. Aprender seria, nesse sentido, antes de receber algo pronto, endereçado à mente, construir outro corpo, um novo corpo com o objeto aprendido, “tão-somente o intermediário entre não-saber e saber, a passagem viva de um ao outro" (DELEUZE, 2006, p. 238).

Ou, como afirma Gallo (2012, p. 8),

[...] aprender é sempre encontrar-se com o outro, com o diferente, a invenção de novas possibilidades; o aprender é o avesso da reprodução do mesmo. [...] isso se dá porque se aprender é relacionar-se com signos, eles, como problemas, pedem uma resposta e esta é sempre singular, inovadora. Cada um reage aos signos de uma maneira; cada um produz algo diferente na sua relação com os signos, o que equivale a dizer que cada um aprende de uma maneira, a seu modo singular.

Na esfera de uma teoria em ato, tal como a tratamos aqui, aprende-se o tempo todo, aprende-se com o corpo inteiro. Uma teoria em ato se transpõe, novamente como nos propõe Spinoza, como uma teoria das afecções, enquanto aumento e/ou diminuição de potências de agir do corpo. Ao nos depararmos com algo que nos potencializa, que nos provoca e movimenta a pensar, estamos diante de potências aumentativas de nosso corpo. Ao nos depararmos com algo que nos paralisa, que nos entristece e nos coíbe - os afetos tristes -, estamos diante de potências diminutivas de nossas potências de agir.

A todo instante estamos produzindo nosso corpo em meio às afecções dispostas nos percursos a que somos submetidos e a todo o tempo prolongamos esse mesmo corpo naquilo que ofertamos ao mundo como resultado de nossos trânsitos e de nossos encontros. Por assim dizer, as aprendizagens com as quais nos deparamos, nessa mesma esteira, são sempre provisórias, efêmeras, submetidas a ordenadas intensivas de atravessamento e passagem.

\section{Corpo fendido}

Diz-se: há corpo sempre que há conteúdo formado, coisa extensa, mistura, cheiro, dobra. Em par com a mente - o pensamento -, o corpo é um dos modos de uma única substância: Deus, conforme sugere Spinoza ${ }^{1}$. Não me refiro aqui

1- Rompendo com Descartes, Spinoza propõe que corpo e mente são constituídos pela mesma substância, a única que há: Deus (natureza). Corpo e mente seriam, portanto, apenas modos dessa substância infinita 
somente a organismos, hierarquia entre órgãos que maquinam e fazem funcionar o corpo como nos acostumamos a pensá-lo, já estratificado - a doença de que Artaud (1983) nos alerta, deus enquanto juízo que a tudo encobre -, mas ao corpo enquanto intensidade, desejo em puro devir, em estado de desterritorialização constante, perseguindo linhas de fuga.

Sob os olhos de Deleuze e Guattari (1997a), que se projetam a partir de Spinoza, há uma geografia, uma topografia que sustenta corpos: partículas em estado de lentidão e velocidade, movimentação e repouso que ganham consistência e extensão em um traço de longitude. Em outro, agora de latitude, há somente a capacidade de afetar e de ser afetado dos/por outros corpos, definidos pelas movimentações e velocidades de partículas do primeiro traço. Esse conjunto constitui uma única natureza para os corpos, que se estabelece em um plano de consistência ou imanência em que permanecem todos os indivíduos, sem haver separação entre coisas ditas naturais e outras ditas artificiais.

Há fenda no corpo, nessa geografia do corpo, sempre que algo escorre, escapa, vaza, desprende-se dessas coordenadas, liberando fluxos e linhas de conexão com o Fora ${ }^{2}$ ordenadas de força e intensidades de devir. Fora, não no sentido oposto ao dentro, como em uma máquina binária, mas enquanto exterioridade absoluta (LEVY, 2011), maquinaria abstrata, desterritorializada e desestratificada. Fora plano de consistência diagramado, Fora - corpo antes do organismo, Fora - corpo-sem-órgãos.

Os corpos, já estratificados, deslocamse no espaço, produzem-se no espaço, criam percursos, mapas, caminhos que ora territorializam o próprio espaço, enrijecendo as linhaseintensidades que correm deliberadamente no Fora absoluto desterritorializado - o que

que ora se expressa através do extenso (corpo), ora do pensamento, respectivamente (mente, ou espírito).

2- 0 conceito de Fora em Deleuze é pensado, conforme aponta Levy (2011, p. 102), como constituinte do "domínio das forças, das singularidades selvagens, da virtualidade, onde as coisas não são ainda, onde tudo está por acontecer". vulgarmente chamamos nada - ora abrem fendas nos estratos e fazem dessas mesmas linhas e intensidades passagens, estratégias para traçar séries de lembranças desse nada ou Fora, que, embora seja coexistente, pelas operações de reterritorialização, é ordinariamente esquecido.

Corpo em campo aberto, espaço que recebe o corpo, espaço que vem ele mesmo a ser corpo, corpo que expulsou ou ainda nem formou o organismo, corpo estratificado que abre fendas para se conectar com o nada, espaço que é nada, nada além de nada.

Não há valorações, máquinas binárias ou essências puras que foram perdidas nessas ordens enunciadas (estratificações e Fora absoluto, territorialidades e desterritorializações, corpo orgânico e corpo-sem-órgãos). Há apenas negociações, interpenetrações, tensores que ora mantêm o corpo enrijecido, estratificado e territorializado, ora lhe permitem movimentarse juntamente às linhas e intensidades absolutas, às singularidades selvagens do Fora.

Formas de conteúdo (misturas de corpos) em pressuposição recíproca a formas de expressão (atributos incorporais) (DELEUZE; GUATTARI, 1995b) que se interpenetram e se autoproduzem, que se movimentam em uma euforia silenciosa, que ora perfazem brechas, atirando-se ao vazio, potencializando linhas de fuga e assim anulando tais valores, ora preenchem os espaços, localizam estratos através dos mais variados agenciamentos que vêm, eles mesmos, a conformar e produzir o corpo organizado.

0 espaço é mais um nada espacial, um nada que pouco a pouco ganha consistência através de um diagrama infinito, do que uma linha temporal, sequencial. Descontínuo, liso e aberto. Para recordá-lo e, em certo sentido, traçá-lo, desenhá-lo novamente, é preciso mergulhar em seu vazio, como o suicida que, ao atirar-se do alto prédio, puxa junto consigo a sobretoalha da mesa ao lado da janela, levando ao espaço alguns dos objetos que estavam em cima da mesma. Sim, essa pode ser a imagem que movimenta a ação: atirar-se do último 
andar de um prédio. 0 intuito de matar-se, a figura do suicida, é o que menos nos interessa. Não se trata de pensar o fim de uma vida, mas o começo de outros tantos agenciamentos e passagens a partir desse ato; trata-se do que circunda a ação-limite de suicidar-se. Isso é o que nos movimenta a pensar: o extremo, a velocidade atingida no meio da queda, o percurso vazio e o tremor do corpo entre o ponto de partida e o de chegada. $\mathrm{Ou}$, ainda, a toalha que flutua silenciosa e não se mantém mais sob os objetos, nem sobre a mesa. A pessoa que está passando na rua ao lado e que não vê a cena, apenas escuta distante o som da ambulância que vem ao encontro da tragédia. Toalha, suicida, objetos, pessoas que passam perto ou longe, em uma fração de segundos, estão em pleno contato com o Fora. Seus trajetos difusos traçam diagramas que acabam por reterritorializar-se no momento exato em que o suicida chega ao chão. É o fim de algo, mas também o começo de muitas outras coisas.

Exercício do extremo, para uma teoria do corpo em ato: torção do pensamento no próprio pensar. Fazer o pensamento acontecer no pensar. Não se trata de vir a conhecer algo para futuramente reconhecê-lo, tampouco de desvelar alguma verdade, mas de criar colagens, sobreposições e justaposições (sobrejustaposições) transcriadoras como saltos no vazio, como cometas em velocidade infinita, como resistência aos tantos modos já conhecidos de produzir os corpos (teóricos, orgânicos, imagéticos), como impessoalidade e como atitude clínica frente ao que é grande demais para ser suportado (DELEUZE, 1997) - crise do Eu como potência inventiva de singularidades sem face. Trata-se de propor encontros e violências que provoquem deslocamentos imprevisíveis e inesperados, que rompam com a harmonia do senso comum, produzindo diferença.

São os próprios corpos que engendram e organizam suas formas de conteúdo e expressão, que configuram seus organismos, seus agenciamentos territoriais estratificados e que os mantêm territorializados, segmentarizados. Há máquinas binárias de todo o tipo (interior enquanto oposto ao exterior, por exemplo), as quais servem de estratégias para que o corpo reproduza-se e espelhe-se melhor. Esse mesmo corpo, já rostificado (DELEUZE; GUATTARI, 1996), seleciona e captura qualquer tentativa de saída dessa maquinaria.

Nos jogos e estratégias de preenchimento de territórios, de enrijecimento, assentamento de linhas e intensidades absolutamente desterritorializadas, os corpos barram e reprimem seus próprios fluxos e, para tudo o que foge ao previsto, passam a acreditar que há algo além das superfícies por trás do plano. Creem que aquilo que eles mesmos criaram pode resguardar segredos, significados profundos, transcendências, as quais são encobertas por camadas que nada mais são que jogos de forças, fluxos desejantes e tensionamentos erigidos por constantes negociações através de diversos mecanismos. Produzem verdades, arquitetam passados lineares, bem engendrados, e invocam sistemas sobrecodificantes e significantes a serem constantemente interpretados.

Um problema aqui se instaura: de que modo conseguir tal façanha? Barrar fluxos, territorializar e traçar segmentos, dar significados, sobrecodificar o que é pura intensidade, o que são somente objetos que caem da janela de um prédio alto, que flutuam no diagrama... É preciso preencher, estriar o espaço liso (DELEUZE; GUATTARI, 1997b) do nada, é preciso dar conta dele e conhecer os pontos de partida e de chegada; não é possível partir da velocidade do percurso ou do meio, não é possível saltar simplesmente no vazio, já que os percursos precisam ser muito bem traçados antes desse salto.

Um corpo fendido, nesse sentido, diante do senso comum, é um corpo falecido, desavergonhado, inutilizado, visto que perdeu seu organismo. É preciso limpar os fluxos, esconder as vergonhas, dar utilidade aos corpos, 
organizá-los, pedagogizá-los. A educação (a Grande Educação), enquanto conjunto de agenciamentos territoriais estratificados, os quais capturam corpos de toda ordem - corpossujeitos, corpos-objetos, corpos-palavras, corpos-conjuntos arquitetônicos, entre tantos outros -, será talvez um dos mais úteis nessa tarefa: suturar o maior número possivel de fendas para que nada escape, para que nada jorre, para que tudo se mantenha em ordem, para que o organismo não se perca. E assim como do verbo se fez rosto e carne, na tentativa de vida, faz-se a morte.

Não será mais permitido suicidar-se, nem abrir fendas, nem conectar-se com o Fora. Se o fizer, é preciso ter muito cuidado, é preciso que tudo esteja muito bem planejado, é preciso que haja redes de proteção por todos os lados e que a toalha não seja puxada junto ao corpo do suicida, até porque aqui ele - o próprio suicida - é a figura central do ato. Nada mais importa. Nem o que cai com ele, nem quem passa na rua ao lado, nem mesmo a sensação do trajeto. 0 que interessa é descobrir a todo o custo o que o motivou a isso e como estava o corpo no chão logo após a experiência do voo livre. É o drama da tragédia o que se quer vivenciar e prolongar.

\section{Então, um corpo-sem-órgãos para a teoria em ato}

Uma das teses teóricas mais célebres de Spinoza é conhecida pelo nome de paralelismo. Ela não consiste apenas em negar qualquer ligação de causalidade real entre o espírito e o corpo, mas em recusar toda eminência de um sobre outro. Se Spinoza recusa qualquer superioridade da alma sobre o corpo, não é para instaurar uma superioridade do corpo sobre a alma, a qual não seria mais inteligível. Talvez uma das principais contribuições do pensamento contemporâneo para os estudos que envolvem os corpos possíveis como foco (seguindo ainda uma linha spinozista/ deleuzeguattariana) seja a de poder operar não mais com um corpo universal, centrado, consciente, que nasceria e morreria predestinado pelas aspirações e pelos discursos da ciência - o qual se definiria somente pelas suas fases, formas, órgãos e funções -, mas sim com um corpo que é, antes de tudo, apenas fluxo de intensidades - antes mesmo de ser energia e/ou matéria, embora abarque também tais instâncias - e que, por sua vez, devém as mais variadas autoproduções de si.

Tal afırmação constata que corpo e ambiente, corpo e natureza, corpo e cultura, corpo e técnica, corpo e mente, entre tantas outras separações binárias que nos acostumamos a fazer - e aí se inclui a clássica separação teoria e prática -, utilizando as lentes da modernidade (iniciada ainda no Renascimento, por volta do século XV), caem por terra, dando espaço para pensarmos um corpo antes do organismo já estratificado, um corpo que, embora encontre uma forma efêmera, por assim dizer, pode se tornar o que quiser, definindo-se apenas por multiplicidades puras, bem como uma teoria que é, antes de tudo, ação, prática: uma teoria do/com o corpo em ato.

Deleuze (2001, p. 118), em uma reedição de seu primeiro livro publicado, intitulado Empirismo e subjetividade, faz a seguinte afirmação

Que não haja e não possa haver subjetividade teórica vem a ser a proposição fundamental do empirismo. E, olhando bem, isso é tão-só uma outra maneira de dizer: o sujeito se constitui no dado. Se o sujeito se constitui no dado, somente há, com efeito, sujeito prático.

Greiner (2005, p. 17), no livro O Corpo, infere que

[...] por mais surpreendente que pareça, contadores, filósofos e escritores têm corpo e negar o seu reconhecimento é apenas mais uma das possibilidades de enterrar a discussão no binômio teoria-prática, que nada mais é do que uma extensão do dualismo mente-corpo. 
Mais especificamente, de que corpo estamos falando quando assumimos como ponto de vista tais afırmações, ou seja, quanto pensamos em uma teoria em ato?

Sem dúvida, de um corpo que, embora possa ser pensando como dado, como objeto teorizável a ser olhado com distanciamento, pressupõe sempre outros corpos que estão por se constituir em tal ação, corpos que se dobram sobre si ao mesmo tempo em que interferem no ambiente à sua volta. Estamos falando de um corpo que não é apenas anteparo para as experiências proporcionadas pelos espaços onde atuamos, tampouco é um substrato somente biológico - um receptor de sentidos naturalmente dado e inquestionável -, em cima do qual se erguem, de forma separada e dissociável, os sistemas ditos artificiais, sociais e culturais, mas de um corpo enquanto fluxo sempre em vias de devir outra coisa, perseguindo linhas de fuga produtivas e experimentativas de aprendizagens múltiplas. De um corpo fendido, afinal.

Artaud (1983) e, posteriormente, Deleuze e Guattari (1996) nos ajudam, na mesma direção que Spinoza, a pensar em um corpo que, expulsando seu organismo hermético, bem acabado, produtivo e funcional, cria para si um corpo-sem-órgãos.

Primeiramente, Artaud (1983, p. 161-162) nos alerta:

0 homem é enfermo porque é mal construído, / Temos que nos decidir a desnudá-lo para raspar esse animalúculo que o corrói mortalmente, / deus / e juntamente com deus / os seus órgãos.

Posteriormente, Deleuze e Guattari (1996, p. 18), tomando para si tal ideia e dando à mesma nuances muito específicas (que aqui, inclusive, interessam-nos mais), afırmam que

Trata-se de criar um corpo sem órgãos ali onde as intensidades passem e façam com que não haja mais nem eu nem o outro, isto não em nome de uma generalidade mais alta, de uma maior extensão, mas em virtude de singularidades que não podem mais ser consideradas pessoais, intensidades que não se pode mais chamar de extensivas.

$\mathrm{Na}$ perspectiva desses dois autores, quando assumimos a prática de um corpo-semórgãos, admitimos um corpo que, na geração e na direção de um plano de esquecimento, ou seja, contrário à incessante retomada da lembrança genética do fantasma psicanalítico, torna-se puro plano de imantação de linhas de fuga e de invenções movimentadas pelo desejo como produção do próprio produzir (DELEUZE; GUATTARI, 1996), na contramão de uma visão do desejo como algo que falta e que carece ser preenchido.

Esse corpo não está pronto como uma essência, como algo escondido que espera por ser encontrado. É preciso buscá-lo, construílo incessantemente, nunca se acaba de fazêlo. Trata-se de uma prática, não simplesmente de um conceito. Trata-se de um corpo sem face, um corpo singular, de infinita potência, o qual não reconhece protocolos orgânicos pré-estabelecidos.

Na oscilação do Corpo que interpreta, um corpo que experimenta, que delira e se abre para o Fora, para o impensado no próprio pensamento, um corpo da imanência que, no lugar de propor significações transcendentais, produz agenciamentos provisórios no aqui e agora, um corpo que rizomaticamente se instala na língua maior e a faz gaguejar, devir-menor.

Investigar a implementação desse corpo plural na esteira do que pode e do que aprende um corpo, leva-nos a transitar por uma zona de virtualidades, mais que de possibilidades somente, uma zona de indiscernibilidade que acaba por variar em um devir-menor de métodos, protocolos e parâmetros já estabelecidos como Maioria $^{3}$. Uma zona onde as coisas, nem sequer

3- A noção de maioria em Deleuze e Guattari (1997a) supõe um estado de dominação, um padrão aceitável em relação ao qual estão as minorias (mulheres, crianças, homossexuais, animais, moléculas, vegetais, minerais etc.). 
as ideias, são ainda, onde tudo pode vir a ser. Denota dizer que, nesse sentido, não podemos falar de técnicas, metodologias e percursos de aprendizagem essenciais, seguros, prefigurados, tampouco em resultados únicos, bem acabados, verdadeiros ou realistas. Podemos falar apenas de uma colagem transcriadora produzida com o que nos afecta de algum modo, fazendo nosso corpo orgânico ganhar outras velocidades, compor com outras imagens que estão no vestígio do que estamos em vias de nos tornarmos.

0 corpo, portanto, antes de ser a gênese dos processos, é como um imã descentralizado que atrai e/ou repele aquilo com o que se movimenta e é, por sua vez, movimentado. Um para-raios que recebe e refrata em outras direções toda a sorte de intensidades. A aprendizagem, nesse preâmbulo, não é algo para além do corpo, nem sequer seu mero produto, mas parte do corpo, formado por fluxos vitais que o interpelam e o cruzam.

É nesse sentido que propor uma teoria em ato - uma aprendizagem do/no corpo enquanto torção do pensamento - leva a nos aproximarmos de tal prática mencionada, a prática do corpo-sem-órgãos, para quiçá propor algumas linhas, como intensidades de devir que atravessem e arrastem os estratos seguidamente outorgados ao ato de aprender na Educação, na vida. Investimos, desse modo, na fabricação de um corpo não necessariamente biológico, antes do organismo estratificado, o qual não se constitui por órgãos ou funções, mas por intensidades selvagens, livres e dimensões como graus ou zonas de potência e intensidade.

Pensar em possibilidades e em aprendizagens pelo viés proposto neste escopo do corpo não orgânico, da teoria em ato - significa pensar em aprendizagens que ocorrem para além da Educação como estrato, mas em uma educação menor, que se dá nos múltiplos trajetos afetivos do corpo, inclusive (e não exclusivamente) em tempos-espaços estratificados. Diz-se de aprendizagens que se orientem por fluxos como linhas de vida que traçam diagramas complexos entre ver, falar e subjetivar-se sobre um Fora, sem, no entanto, abandoná-lo. Aprenderes que engendrem o pensamento no próprio pensar e o coloquem em movimento no sentido de buscar um ainda impensado.

\section{Teoria que é ato, pensamento que é criação}

Pensar [...] é um exercício perigoso. [...] é sempre seguir a linha de fuga do voo da bruxa. [...] não pensamos sem nos tornarmos outra coisa, algo que não pensa, um bicho, um vegetal, uma molécula, uma partícula, que retornam sobre o pensamento e o relançam (DELEUZE; GUATTARI, 1992, p. 58-59).

Se, como afirmam Deleuze e Guattari (1992), a filosofia, assim como a arte, antes de ser um exercício de mera contemplação, pretendese um exercício de criação. Se a arte materializa perceptos e afectos que vão além da simples sensação e percepção, mas congelam no tempo um bloco que é capaz de arrastar nosso ser para um lugar onde seria praticamente impossível dizer Eu (DELEUZE; GUATTARI, 1992), ou seja, manter nosso ego centrado, o que a filosofia faz é criar conceitos que sejam, de forma imanente, operados no mundo, na vida prática. 0 filósofo é um criador e, por sua vez, o pensamento é pura intensidade de criação.

Procurando ampliar tal afirmativa e tentando estabelecer um paralelo entre filosofia e pesquisa, entre as ações do filósofo e do aprendiz, sem, é claro, afirmar que se trata de sinônimos, poderíamos nos ocupar do pensamento - material que, parece-me, pertence às duas atividades mencionadas (filosofia e aprendizagem) - como criação de universos possíveis, de noções operáveis, de elementos constituintes de potências capazes de deflorar a mente e tirá-la de seu estupor natural para fazê-la criar corpo com o mundo.

Movimentar aprendizagens que se constituam em meio a tal perspectiva 
referendada no decorrer do texto, articulando uma teoria em ato, é um desafio, tanto para quem as produz quanto para quem se dispõe ao convite de operar com elas. Há de se ter coragem e estar disposto a provocar uma torção no pensar de modo a colocá-lo em movimento de produção, não de re-produção. Há de se ter coragem para buscar - re-criar - corpos-semórgãos, onde só se encontram intensidades e graus sem hierarquização, onde aprendiz e aprendido são apenas distâncias, faces de uma mesma singularidade.

Um dos questionamentos que podem surgir é: que possibilidades há mediante uma instância prática, visto que o trânsito por uma chamada teoria do corpo em ato aqui proposta nos parece ser resultante somente de injunções e articulações teóricas? Gallo (2010, p. 56), também amparado pelo pensamento deleuzeano/deleuzeguattariano, ajuda-nos a elucidar tal demanda pontuando que

[...] à teoria não compete explicar a prática ou mesmo possibilitá-la, assim como não compete à prática alimentar a teoria ou manifestá-la na luta social. É impossível dissociá-las, sobretudo porque, se saímos do âmbito da representação, as totalizações já não fazem mais sentido e deixam inclusive de ser possíveis.

Visto isso, ao invocar certos conceitos, imagens e noções a fim de minimamente repensar algumas das relações que se estabelecem em um âmbito que associa corpos, indivíduos, organismos e ambientes, também se está lançando possibilidades experimentativas no sentido prático, para além de mecanismos simplesmente teóricos. Ainda segundo Gallo (2010, p. 58),

[...] se a teoria é uma ferramenta, ela faz sentido enquanto é usada e gera circuitos imediatos com as várias práticas, que por sua vez operam alterações nas ferramentas ou mesmo implicam na construção de novas ferramentas teóricas.
Exercitar o pensamento, provocar nele torções e violências, colocar as teorias em funcionamento já se trata de uma ação prática que, em seu próprio ato, modifica o que está sendo teorizado, intervindo em outras possibilidades produtivas da própria ação.

Apostar em uma teoria em ato, portanto, retomando a questão feita ainda por Spinoza (o que pode um corpo?) e ampliando-a para o que pode e o que aprende um corpo?, significa escapar da lógica representacional ou da crença em uma essência escondida nas entrelinhas, a qual precisaria ser decifrada a fim de ser acessada, para encarar o pensamento como criação, como possibilidade.

Ou seja, significa perguntar "que violência se deve exercer sobre o pensamento para que nos tornemos capazes de pensar, violência de um movimento infınito que nos priva ao mesmo tempo de poder dizer 'Eu'?” (DELEUZE; GUATTARI, 1992, p. 73). Trata-se de ir além de um Eu autônomo que acessa o conhecimento, para se tornar uma impessoalidade em devir no próprio movimento do pensar. Trata-se de dar outras velocidades ao pensamento, de fazê-lo percorrer mapas não representacionais, mas inventivos, produtivos de percursos impensados; de tensionar o que é dito e o que é visto a fim de propor outras dobras sobre o que são somente virtualidades, outras linhas de subjetivação.

\section{Escrever e ler: teoria e corpo em ato}

À guisa de finalizar este texto sem, no entanto, fechar a discussão, para que outras linhas possam ser traçadas a partir do que aqui foi proposto, consideramos retomar a problemática inicial de outra forma: se, como já visto, não se sabe tudo o que pode um corpo, é preciso levá-lo a um limite onde categorias orgânicas pré-estabelecidas não sejam mais consideradas e, desse modo, produzir com ele um plano onde se congregam elementos afetivos que aumentam e diminuem sua potência de criação, que o levam a devires diversos e que 
impossibilitam sua capacidade de proclamar um Eu autônomo que seria capaz de, do alto de seu suposto saber asséptico, clínico, registrar em pesquisa o contexto que, com distanciamento, vê e avalia.

A escrita e a leitura, nesse sentido, ou, a escrileitura (CORAZZA, 2008) - para não acabar equivocadamente propondo tais ações como anteparo ou medida engessada em relação a uma ou outra -, parecem atravessar a aprendizagem, tanto quanto atravessam a filosofia. E parecem ser, como afirmam Deleuze e Guattari (1995a), casos de devir sempre outra coisa, antes de serem formas de cristalizar nosso ser ou as coisas sobre as quais lemos e escrevemos.

Pensamento e escrileitura, desse modo, parecem nutrir uma relação amorosa e de contaminação de fluxos corporais onde se pensa para escrever e ler, escreve-se para ler e pensar e lê-se para pensar e escrever. 0 corpo se liquefaz e se espalha, jorra na escrita, encharca o texto. A mão trasborda e se desmancha como a aranha se desfaz na teia, ao modo de uma hifologia, sendo hyphos o tecido e a teia da aranha (BARTHES, 2010).

0 texto que coloca o pensamento e o corpo em ato e que atravessa a aprendizagem, nessa perspectiva, é (junto com o corpo que se desorganiza para produzi-lo) também um corpo-sem-órgãos, um agenciamento de afetos e de passagens de fluxos que, se por um lado procuram significar algo, dizer alguma coisa, por outro, estabelecem apenas um espaço informe onde nada é ainda, onde tudo está em vias de ser, onde pensamento e corpo ainda são apenas possibilidades:

Um livro não tem objeto nem sujeito; é feito de matérias diferentemente formadas, de datas e velocidades muito diferentes. Desde que se atribui um livro a um sujeito negligencia-se este trabalho das matérias e a exterioridade de suas correlações
[...]. Num livro, como em qualquer outra coisa, há linhas de articulação ou segmentaridade, estratos, territorialidades, mas também linhas de fuga, movimentos de desterritorializações e desestratificação. As velocidades comparadas de escoamento, conforme estas linhas, acarretam fenômenos de retardamento relativo, de viscosidade ou, ao contrário, de precipitação e de ruptura. Tudo isto, as linhas e as velocidades mensuráveis, constitui um agenciamento. [...] É uma multiplicidade (DELEUZE; GUATTARI, 1995a, p. 11-12).

Considerando uma teoria e um corpo em ato, nunca teremos uma escrita ou uma aprendizagem plenamente acabados, a compreensão máxima de uma noção, o estabelecimento fixo de qualquer verdade. Teremos, sempre, somente uma rede no mínimo extensa de possibilidades, de amarrações, vias, acessos, tensões - como uma cartografia, um labirinto, uma colagem - por onde nos movimentamos e damos por assentadas certas coisas em um determinado espaço de tempo. Teremos apenas velocidades diferentes de escoamento daquilo que enunciamos coletivamente mediante os agenciamentos que somos capazes de produzir rizomaticamente a partir do que nos afeta.

Escrever (e ler) qualquer coisa, nesse sentido, é mais o trabalho de quem produz realidades mistas, híbridas, plurais, do que de quem reproduz uma única realidade engessada. Não deixa de ser o trabalho do agrimensor de um espaço informe, inacabado, de um de-Fora (onde tudo poderá vir a ser, de acordo com o modo com que tal e qual escrita/leitura puder ser rearticulada, de acordo com os limites impensados que o pensamento puder alcançar), do que o trabalho de um sujeito dotado de um organismo pleno capaz de significar e sobrecodificar códigos. 


\section{Referências}

ARTAUD, Antoni. Para acabar com o julgamento de Deus. In: ARTAUD, Antoni. Escritos de Antonin Artaud. Tradução, seleção e notas de Cláudio Willer. Porto Alegre: L\&PM, 1983. p. 145-162. Título original: Pour en finir avec le jugement de dieu.

BARTHES, Roland. 0 prazer do texto. Tradução de Jacob Guinsburg. 5. ed. São Paulo: Perspectiva. 2010.

CORAZZA, Sandra Mara. Os cantos de Fouror: escrileitura em filosofia-educação. Porto Alegre: Sulina: UFRGS, 2008.

DELEUZE, Gilles. Crítica e clínica. Tradução de Peter Pál Pelbart. São Paulo: Ed. 34, 1997.

DELEUZE, Gilles. Diferença e repetição. 2. ed. Rio de Janeiro: Graal, 2006.

DELEUZE, Gilles. Empirismo e subjetividade: ensaio sobre a natureza humana segundo Hume. Tradução de Luiz B. L. Orlandi. São Paulo: Ed. 34, 2001.

DELEUZE, Gilles. Proust e os signos. 2. ed. Rio de Janeiro: Forense Universitária, 2003.

DELEUZE, Gilles; GUATTARI, Felix. Mil platôs: capitalismo e esquizofrenia. v. 1. Tradução de Aurélio Guerra e Célia Pinto Costa. Rio de Janeiro: Ed. 34, 1995a.

DELEUZE, Gilles; GUATTARI, Felix. Mil platôs: capitalismo e esquizofrenia. v. 2. Tradução de Ana Lúcia de Oliveira e Lúcia Cláudia Leão. Rio de Janeiro: Ed. 34, 1995b.

DELEUZE, Gilles; GUATTARI, Felix. Mil platôs:capitalismo e esquizofrenia. v. 3. Tradução de Aurélio Guerra Neto et al. Rio de Janeiro: Ed. 34, 1996.

DELEUZE, Gilles; GUATTARI, Felix.Mil platôs: capitalismo e esquizofrenia. v. 4. Tradução de Suely Rolnik. São Paulo: Ed. 34, 1997a.

DELEUZE, Gilles; GUATTARI, Felix. Mil platôs: capitalismo e esquizofrenia. v. 5. Tradução de Peter Pál Pelbart e Janice Caiafa. São Paulo: Ed. 34, 1997b.

DELEUZE, Gilles; GUATTARI, Felix. 0 que é a filosofia? Tradução de Bento Júnior e Alberto Alonso Muñoz. Rio de Janeiro: Ed. 34, 1992.

GALLO, Silvio. Filosofia da diferença e educação: 0 revezamento entre teoria e prática. In: CIARETO, Sônia Maria; FERRARI, Anderson (Orgs.). Foucault, Deleuze e Educação. Juiz de Fora: UFJF, 2010. p. 45-63.

GALLO, Silvio. As múltiplas dimensões do aprender... In: Congresso de Educação Básica - COEB: aprendizagem e currículo. Anais do... Florianópolis: COEB, 2012. Disponível em: <http://www.pmf.sc.gov.br/arquivos/arquivos/pdf/13_02_2012_10.54.50. a0ac3b8a140676ef8ae0dbf32e662762.pdf>. Acesso em: 15 jan. 2014.

GREINER, Christine. 0 corpo: pistas para estudos indisciplinares. São Paulo: Annablume, 2005.

LEVY, Tatiana Salem. A experiência do fora: Blanchot, Foucault, Deleuze. Rio de Janeiro: Civilização Brasileira, 2011.

SPINOZA, Benedictus de. Ética. Tradução e notas de Tomaz Tadeu. 3. ed. Belo Horizonte: Autêntica, 2010.

Recebido em: 18.11.2014

Aprovado em: 24.03.2015

Cristian Poletti Mossi é professor adjunto da Universidade Estadual do Rio Grande do Sul (UERGS). Doutor em educação e mestre em artes visuais. Tem focado seus estudos na interface com as filosofias da diferença. É membro pesquisador do Grupo de Estudos e Pesquisas em Arte, Educação e Cultura (GEPAEC). 